\title{
Deciphering the "elite subaltern": An Analysis of the Translated Life Writings of Malayali Brahmin Women
}

\begin{abstract}
$\underline{\text { Abstract }}$
Translation has always embarked upon the task of conveying and communicating to a larger audience transcending the spatial and global dynamics of a particular language. My paper titled "Deciphering the "elite subaltern": An Analysis of the Translated Life-

Writings of Malayali Brahmin Women" explores the translated memoirs of Devaki Nilayamgode and Lalithambika Antherjanam. The proposed study intends to analyse the multiple linguistic and cultural nuances associated with the translation endeavour. It endeavours to examine the role of translation as a feminist empowerment tool in conveying the life histories of the women across culture.
\end{abstract}

Divya.N.

Key words: Culture, Gender, Language, Society, Translation.

Woman must write herself; must write about women and bring women to writing, from which they have been driven away as violently as from their bodies ... Woman must put herself into the text ... by her own movement (Cixous 1976: 875).

This study purports to analyse the inscribing and translating of feminine consciousness by women themselves and others, inducing an introspecting spectatorship in the form of readers into her individuality. It explores the documentation of women's lives specifically in the context of the early twentieth century Kerala culture and society.

The paucity in the composition of the early twentieth century feminist autobiographies in Kerala went up to the late mid 
1970 's and 1980's posterior to which, Malayali women commenced to articulate and textualise their early lives in a deterministic and affirmative mode. One of the selected texts titled Atmakathakkoru Amukkham (Preface for an Autobiography) by Lalithambika Antherjanam appeared in 1979. "In a brief foreword to the memoir, Lalithambika writes that on her seventieth birthday she decided to publish a few essays that touched on her past and on issues that deeply concerned her" (Krishnankutty1998: xxvii). Analogous to Lalithambika Antherjanam's rendition Devaki Nilaymgode elucidates that "In 2003, just after my seventy-fifth birthday, I published a slim book of my memoirs (Nashtabodhangalillathe) which literally means "with no sense of loss or regret"" (Nilayamgode 2011: vii).

However even after production, most of these self-residues that were inter-texted into the logo-centric framework, took considerable time to get into the print light. This study addresses the perception of the "elite subaltern," referring to the inferior position imposed on the Namboodiri women, due to gender discrimination practices. It examines the plight of the Namboodiri women in Kerala, analysing their lives during the early twentieth century in the backdrop of the social, religious and cultural history. It purports to examine this concept of the "elite subaltern" with reference to the translated memoirs of Lalitambika Antherjanam and Devaki Nilayamgode, locating their life writings in the broader framework of the regional social history of Kerala in translation.

\section{Foregrounding the memory and the self}

Translations of women's writing have always embraced the vision of the oppressed and the downtrodden in the act of bilingual documentation. The biographical recording and re-rendering of 
feminist lives has been perpetually varied in its assertion and approach. The early twentieth century feminist biographies and autobiographies enunciated the escalated desire for women's self articulation, transcending the established frameworks of biographical rendering. They represented a new self-oriented dynamics of emancipation and method of embodying women. Every text of feminist self-writing indulges in the exercise of conscious or unconscious encapsulation of the female body and mind within the critical frames of self-encryption. They underline and recognise the common denominators of subjectivity in these diverse recreations of feminist individuality.

The translated memoirs of Lalithambika Antherjanam and Devaki Nilayamgode befit the category of self-documented lifewritings transforming the subjective and experiential individual memory. They subtly and explicitly constitute and improvise an intersection between the word and the feminine self consciousness. The authorial choice of these women stems from her specific and broader interest in analysing the ubiquitous elements of feminine subjectivity illustrated in these translated retellings of women's lifestories.

Analogous to other feminist autobiographies, the selected texts cannot be compartmentalised or classified as simple, linear narratives of women's lives. They are complex and complicated in their construction, comprising both conscious and unconscious politics of discourse. These textualised reflections and recollections are endowed with an inherent experimentation. They rationalise the perception that the "way in which the life-histories of individual women can provide insight into the general situation of women is made quite explicit in many recent biographies written by feminist history" (Caine 1994: 251). These memoirs of Brahmin women, 
based on the early twentieth century Kerala history juxtapose their personal lives with the social, political and cultural history.

It has been observed that "The very choice of texts to work with, then, poses an initial dilemma for the feminist translator" (Chamberlain 2000:326). "Women translators [had always] wondered why they were working on texts which suddenly seemed alien to them, texts whose premises they could not share. At the same time, women were discovering feminist writing with which they felt intense affinities" (Simon 1996: ix). The chosen translated memoirs forms an answer to the intense affinity and universal bonding shared by women transcending age, caste and distance.

The translator's notes in the chosen memoirs explicitly and precisely state their specific and sincere affinity to the memoirs and the authors. They had evinced and enunciated their interest in the life stories of these Brahmin women who have experienced contemptuous and condescending treatment inside their upper caste society and family, in sharp contrast to the dignified status adorned by their male counterparts.

The translators acknowledge the fact that "Antharjanams" have always been a source of great fascination in popular imagination in Kerala. To an outsider's eyes they were living exotica" (R. Menon 2011: xii). Their endeavours in fact stem from the ironical awareness of the simultaneous significance and restrictions ascribed to Malayali Brahmin women in the early twentieth century Kerala society. Their life-writings emerge as a spontaneous counter flow to their suppressed plight, despite the prevalence of radical social movements of that time as "namboodiri girls remained largely untouched by those impulses; they continued to live very restricted lives" (Krishnankutty 1998: xiii). 


\section{Translation and the History of "Elite" Oppression:}

Writing and translating any autobiography involves resistance facilitated through a perpetual process of self recasting. Devaki Nilayamgode's Antharjanam: Memoirs of a Namboodiri woman and Lalithambika Antherjanam's memoirs are no exceptions. Articulation of the recognition of a prevalent historical undesirability based on gender characterises the narratives. The biographical recounting erases the temporal boundaries of the past through an effective mnemonic reconstruction of the feminine experiences in the social and cultural context.

At the onset itself the memoirs delineate the societal disapprobation of womanhood. Lalithambika Antherjanam reminiscences that "her society considered it a curse to be born a girl" while Devaki Nilayamgode recounts that "In those days, the birth of a girl in illams was not considered auspicious" (Antherjanam 1998:133; Nilayamgode 2011:8). The translated memoirs outline the commencement of the cultural contempt and accusation of inauspiciousness heaped upon women, right from their birth. They acknowledge the history of oppression and assume the responsibility of conveying the deplorable plight of the "elite subaltern" across the cultures. "The stories and autobiographical essays chosen for translation here represent ... the plight of anterjanams who, more often than not, stand in for women as a whole" ( Krishnankutty 1998:xxix). They emerge as cross-fertilized bilingual endeavours informing the deplorable plight of namboodiri women, transcending the geographical barriers. To accentuate the purpose of the translated text, "A reader might well trace through these texts a history of the women's movement, an ongoing feminist engagement with the aesthetic, a dream of the nation," despite their regional and societal specificities (Krishnankutty 1998: xxix) 


\section{Girl to Woman}

In this section I wish to examine and explore the inherent nuances and subtleties in the translated memoirs specifically relational to the portrayal of the feminine maturing phase including the puberty and the menarche. I would prefer to critically observe and analyse the role of translation in recreating these gender specificities in the context of regional history.

The translated memoirs function as bildungsroman through temporal delineations of the physical and psychological growth of a woman. They adumbrate the social and cultural intricacies associated with the Brahmin girl's evolution to womanhood. According to the life writings, the convention of "Uduthu Thudangal" signifying the discarding of loin cloths made of leaf and starting of wearing cotton undergarments "was the first step towards womanhood."(Nilayamgode 2011:31)

The translated memoirs elaborate on the practices and customs, during the transition phase from puberty to womanhood. They explicate the conventions like child marriage before puberty.

The memoirs discuss the discrimination heaped upon the women during post-puberty. "A girl who had come of age was not supposed to step out of the illam or even see the portico" (Nilayamgode 2011:110). Analogous to Devaki Nilayamgode's critique Lalithambika Antherjanam explicates the trauma she faced on attaining puberty. The memoirs elucidate the societal dread and anxiety associated with menstruation.

Lalithambika Antherjanam recounts that when "she reached puberty, the house looked and felt as if someone had died. Her 
mother wept, so did the rest of the family, and the servant women, and seeing them, she too could not help crying" (Antherjanam 1998:138). Analogous to her experience Devaki Nialaymgode's memoirs explicate that on attaining puberty she retreated into her "illam like a bird with clipped wings" (Nilayamgode 2011:46).

In fact the translated memoirs expound the escalating enforcements of cultural and social norms upon women during the post puberty phase reducing her to the status of a corpse.

They explicate the laborious rituals associated with menarche and the amplified seclusion post puberty retaining the original glossary.

Akin to Susie Tharu's observation the translators of Devaki Nilayamgode's memoir also faced the same dilemma of whether to retain the cultural terms or substitute them with their linguistic equivalent counterparts despite the full fledged resonance in cultural correspondence. They cite the example of the word 'irikkanammaamar' and how the initial translations had converted the word into its meaning woman attendants. However according to the translator "the subsequent series of revisions ... [retained] the native term in order to preserve its rich meaning as well as local flavour. The same logic decided the use of the 'amma' and 'achan' in preference to 'mother' and 'father' "(R.Menon 2013: xv)

\section{Domestic Space, Institutions and Namboodiri Women}

Devaki Nilayamgode enumerates her domestic restrictions during her early childhood and puberty while Antherjanam explicates her domestic situation of having to exist in a society that regarded girls as curse. Compared to Nilayamgode's rendering of the 
lack of domestic support in the context of active feminist emancipation during her early childhood, Antherjanam explicates her reception of paternal and maternal support as "her father took great care not to let her realise that she had been born into a society that did not believe in bringing up girls as human beings" (Antharjanam 1998:134).

The memoirs demonstrate the Brahmin households or illam as a domestic space of ostracised and secluded feminine subjectivity. They effectively depict the "grim unsentimental iron-rule of hierarchy within the traditional domestic space of the Malayala Brahmin homestead" through the lens of the memory of protagonist (Devika 2011: xviii).

The translated narratives expatiate upon the marital and conjugal aspects of Brahmin women. They trans-create the domesticated women in the socially appropriated universe of marriage. Both Devaki Nilayamgode and Lalithambika Antherjanam explores the custom of "sambandham" or the practice of the younger brothers marrying from the Nair community as the tradition permits only the elder brother in a Kerala Brahmin household to marry from his own community. The memoirs portray the subsequent sufferings inflicted upon the Namboodiri women as a result of this sambandham including younger Brahmin girls marrying older Brahmin men, sometimes even more aged than their father. The narratives also depict the fact that the institution of "Sambandham" which meant that "only the eldest son could marry from his own caste" lead to polygamy resulting in older Brahmins marrying younger girls" (Devika 2011: xx).

While explicating the domestic and family life of Namboodiri women, the translated memoirs explicitly outline the 
deplorable plight of widows. They accentuate the fact that "In the Namboodiri community, nothing was considered a greater sign of misfortune than the sight of a widow" (Nilayamgode 2011:78). Both the translated versions echo the emotional anguish and laceration experienced by widowed Namboodiri women.

\section{Mothers and Daughters}

The translated memoirs discuss the deep attachment and the profound relationship of the protagonists to their mothers and their perspective on the role of the women as mothers. The narratives simultaneously juxtapose motherhood as "an eternal truth, and also an ordinary occurrence" (Antherjanam 1998: 173). Both the protagonists expound their conflict with their mothers on traditional matters. Devaki Nilayamgode exposits the seemingly ambivalent attitude of her mother who in spite of her belief that women should possess psychological and physical security in her societal and domestic environment was reluctant to endow her daughters with freedom due to fear of transgression. She recounts that her mother "did not give us, her daughters, any freedom because she believed that girls should not be encouraged to think and act independently" (Nilayamgode 2011:11). Analogous to Devaki Nilayamgode's portrayal Lalithambika Antherjanam explicates her conflicts with her mother who feared her daughter's rebellious attitude. According to Antherjanam "tradition dominated" her mother who was "terrified of calumny" (Antherjanam 1998: 175).

The translated memoirs effectively recreate the writers' demonstration of the complex relationship they shared with their mothers. Antherjanam reminiscences her mother's shock, anguish and protest when she came back home after attending the Nair meeting, discarding her "marakuda" and "ghosha." She explicates 
that when she "abandoned the system of seclusion" personified by "marakkuda," the traditional umbrella used for the purpose of hiding the body and face of Namboodiri women, her mother "lamented as if" she had died, or been cast out" (Antherjanam 1998:177). The translated memoirs in fact effectively recounts the prevalent cultural and societal assumptions nourished in the upper caste household of early twentieth century Kerala regarding the maternal duties and obligations of women.

\section{Women as Writers and Translators}

In this section I wish to elaborate and explicate the ambiguity and complexity associated with the role of women as translators and writers contextualising them in the backdrop of the selected autobiographies. The chosen memoirs with women as translators and authors become pertinent in the present context of an assumed and sustained independence initially self-cultivated by the writers. In this juncture it becomes important to acknowledge and realise that the two writers Lalithambika Antherjanam and Devaki Nilayamgode chose to self -document their lives only after becoming confident of their ability to endure any kind of conflict that emerge out of these life-writings.

The translators explicate the qualities and characteristics of the writings. In their perspective Nilayamgode's memoir "honestly sketches some of the beliefs, practices, and rituals of the Namboodiris that made life within their closed system insufferable for women" (Radhika 2011: xii). Similarly Antherjanam's writings are "startling and insightful documents of a moment in which the struggle against the repression and incarceration of women from the namboodiri Brahmin community came together in quite an exceptional conjuncture with protests against caste discrimination ... 
and challenges to colonial rule" (Tharu 1998:viii). In short the translation endeavours sprang up from the significant realisation of the social, cultural and historical inter-textuality embedded in the texts. They refused to attenuate the autobiographies merely to the literary realm.

The same gender of translators and authors become pertinent in reducing the linguistic and logo-centric complexities associated with the chosen texts. However the translators acknowledge the fact that "Working within the conventional hierarchies ... the female translator of a female author's text and the male translator of a male author's text will be bound by the same power relations: what must be subverted is the process by which translation complies with gender constructs" (Chamberlain 2000:327).

The translators of the selected memoirs endeavour to conform and transform the gendered nuances and implied subtleties implied in the words through a bilingual re-appropriation of the texts. They have acknowledged and expressed their emotional affinities with the chosen texts and the authors. They have articulated their concern and respect for the authorial endeavour. In relation to Devaki Nilayamgode's memoir, one of the translators remarks that "Even though she chronicles a life of deprivation, lived with great hardship, Nilayamgode has chosen not to be judgemental about the people and events in her life. There is no discernible anger at the unfairness of the treatment of women, and of herself in particular" (I.Menon 2011: ix). A distinguished tone of empathy and sympathy characterises the translators' reaffirmation with the authors. They acknowledge the reality that 'the antharjanams' aweinspiring exclusivity concealed the cruellest form of patriarchal oppression that robbed them not only of independence and education but even the simplest and most innocent of joys" (R.Menon 2011: xii). 
While exploring the role of translators in these trans-created autobiographies we realise that "the woman translator in this case is not simply subordinated, she is not the author's secretary ... Translation is writing; that is, it is not translation only in the sense of transcription. It is a productive writing called forth by the original text" (Derrida 1985: 153).

The translators of the chosen life writings have undertaken the struggles, pain and effort to transform the self-consciousness in the text through the interface of an alien language. According to them translating emotions proved to be the biggest hindrance despite their persisting feelings of sympathy and empathy. During the process of translation they realised that "The different ways in which various people react to emotional turbulence create a hurdle in transcreating anger, pain, joy or love in a foreign language. This was the major problem I faced while translating the text" (I.Menon 2011: $\mathrm{x})$.

The chief task of the translator pertaining to Devaki Nilayamgode's book in her perspective was to expose "the steely quality behind the apparent pliancy" and calmness of her words. The translators in both the endeavours were entrusted with the task of bringing forth before the readers across the globe "a thinking, probing, questioning, intelligent mind which rejects the false values of society" ((I.Menon 2011: ibid).

Parallel to the semantic task of cultural and global transmission associated with translation, the narratives focussed on the semiotic section. Teasing "out the nuances of the words and their contexts" figured as "an uphill task" for the translators in the context of the autobiographies (I.Menon 2011: ibid). Analogous to other translation endeavours, trans-creating the implied semiotics and 
semantics of the textual language formed a challenge for the translators. Indira Menon's “difficulty stemmed from Nilayamgode's language, itself, which is simple, unadorned, and stark to the point of being bare" (I.Menon 2011: ibid).

According to her "bringing emotional upheavals to the surface without making them obtrusive" proved to be a challenge as "the text does not allow you to speak openly about the struggles" (I Menon 2011: xi). The narrative acknowledges the fact that "The semiotics of one language and culture differs from another, rendering some signs not easily comprehensible in the target language" (I.Menon 2011: ibid).

Transgressing these differences and discrepancies through a universal language proved intricate for the translator. The knowledge that "The translator, thus has to walk the thin line between close adherence and transcreation, which may leave her open to the criticism of having departed from the text" permeated the endeavour to adhere as much as to the text (I.Menon 2011: ibid). Howsoever Radhika Menon, the other translator of the same text primarily accentuates on the subjective affinity and empathy between the translator and the author. She attributes the chief impulse of her translation endeavour to the fact that "when a text strikes a chord in a reader's heart, the natural impulse is to share it with a larger community that may derive equal pressure out of it'(R.Menon 2011:xi-xii). She shares Indira Menon's perspective that the memoir "reveals the inner beauty of the person who authored it. Despite serious setbacks (being deprived of formal education being the most crucial among them) Nilayamgode betrays no sense of bitterness or righteous indignation. This tonal balance informs the entire narrative" (R.Menon 2011: xiii). Attuning to Indira Menon's observation she too perceives that the "quality of 
dignified restraint ... posed the greatest challenge in translation" (R.Menon 2011: xiv).

The translators' note discusses the cultural difference between the host and the target language. According to their perspective ensuring linguistic and cultural equivalency proved to be the greatest challenges in the process of translation. The knowledge that a translation can "nevertheless be a stumbling block to the readers of its English version and deny them a peek into the subtle historical or cultural nuances of certain seemingly mundane observations that Malayalis, conversant with the social movements of the state, can access without any difficulty" permeated the adhering endeavour to the host text (R.Menon 2011: xiv). Hence the translator exclaims that she preferred a more "emphatic version" than a loyal one in her translation when the translator "runs the risk of muffling the potency of the detail" due to her adherence to the text (R.Menon 2011: ibid).

Both the translations have endeavoured to erase the possibilities of cultural anonymity and gender alienation through strategic linguistic tools for cultural assimilation including glossary and foot notes. The employed Sanskrit and Malayalam religious glossary accentuates and exposits the vulnerability of the "aristocratic" women who has to succumb to the orthodoxy, that restricts even their physical mobility and rights. Terms like "uduthu thudangal", "antahpuram" meaning the inside of home and names of Malayalam months like "Dhanu" are retained as the same in the narratives, for cultural specificity. A critical exploration of Gita Krishnankutty's translation endeavour by the concerned translation network itself opines that "we have often retained a Malayalam word even when we provide a near equivalent in parentheses to mark the dissonance and to suggest that the reader should strain beyond the 
restful English and reach towards what more might be at stake in the formulation" (Tharu 1998: ix). Glossary forms the soul and the window of the translated memoirs facilitating cultural equivalence through the linguistic retaining of the native words in the global language.

However the translators admit and acknowledge the role and limitation of glossary in translation. According to them "certain other native words would not permit deferment of their explanatory notes to the glossary. In such cases, though very rarely in this text, I had to take a bit of liberty and bring the meaning into the text" (R.Menon 2011: xv). She cites the "appending of the phrase 'literally meaning "object" as the erring antharjanam was called' to the word 'saadhanam' was necessary lest the non-Malayali reader should overlook the heavy patriarchal bias embedded in the trial of Kuriyedathu Thaatri'"( R.Menon 2011:ibid). Akin to the assertion of Radhika Menon and Indira Menon, the translation initiators of Lalithambika Antherjanam's memoirs delineate that they "have tried to develop a practice of translation and provide introductory material, notes, and glosses that retain the historical and regional specificity of the struggles Lalithambika depicts," for the purpose of cultural familiarity with the alien readers (Tharu 1998: ix). In short the translators have profusely endeavoured and struggled to retain and convey the cultural nuances effectively.

Unlike Devaki Nilayamgode's memoir, Lalithambika Antherjanam in her autobiography addresses herself in the third person, as she recounts her persistence "in her chosen way of action with extraordinary self-confidence, even at the risk of being considered insolent" (Antherjanam 1998: 142). The authorial third person narration intended for a detached articulation is trans-created in the translation with the simultaneous reclaiming of the third 
person subjectivity by the author and the translator. The distinguishing and sporadic exploration of the translators' note, constantly exclaiming and examining the multiple aspects of the memoirs in fact proved insightful

A selective ambivalence of articulation constitutes the urge for self documentation in the life writing of these dominant women. The explicit and implicit referential paradigms inherent in the selected texts exercise a feminist perception of life. Both the memoirs emphasise the conflict encountered by women in the multifaceted role of writers and translators. While Lalithambika Antherjanam explicates "the conflict between the individual as an artist and the individual as a member of the family," Devaki Nilayamgode expounds the truth that "I had never thought I could write at all” (Antherjanam 1998:160; Nilayamgode 2011: vii).

The narratives also explore Namboodiri women as authors. Lalithambika Antherjanam's memoir expounds the role of women in literature. She discourses on the hurdles encountered by Namboodiri women and women of Kerala in the field of creativity as "hardly any women of the last generation in Kerala, or indeed in the whole world, dedicated themselves to the creation of literature ... not because we lack talent or power of expression, but because the way in which we were crushed by circumstances." She explicates that "women of highborn families may not allow their voices to be heard outside the home" (Antherjanam 1998:158). Her views echo Devaki Nilayamgode's perspective regarding the suppression of creative faculties and critical reasoning of women by restricting their opportunities for education The narratives in fact assume the proportion of meta-creative texts explicating and locating the process of feminine creative faculty in pertinence to their domestic situations. 
In short the chosen translated autobiographies primarily emerge as gendered narratives accentuating on the role of women as translators and writers. They construe a selective form of literary self -assertion, transgressing the patriarchal hideousness where a new mode of resistance writing and transference replaces the early constricted articulations of the feminine self.

\section{Namboodiri Women and Reform Movements}

The translated memoirs of Devaki Nilayamgode and Lalithambika Antherjanam explicate the significance of reform movements in the lives of Namboodiri women. The translators note and the introduction to the memoirs expound the thrust laid upon by the various reform movements in rectifying the lives of Namboodiri women in accordance with their self-perception and awareness. "In self -knowledge, the images of the ineffectual Nambutiri and the passive and suffering Antharjanam take shape as the objects to be transformed through reform, and the subjects of Malayali Brahmin reformism are invited to identify themselves with these images and finally overcome them" (Devika 2007:119). The narratives in fact hints upon the patriarchal ideological manipulation in the feminist reform movements.

The translated works delineate the attempts of reform by the Yogakshema Sabha, the community formed to help Brahmins in relation to the upliftment of Namboodiri women. The memoirs echo the critical observation that "Community building efforts among the Nambutiris began early in the twentieth century with the formation of the Nambutiri Yogakshema Sabha (henceforth,YKS) in 1908" (Devika 2007:124). They treat Yogakshema Sabha as a key force in the feminist emancipation urge and acknowledge the significance of "a period of activism that succeeded in bringing mere homemakers 
like me to the forefront of public life" (Nilayamgode 2011:154).

Parallel to the explication of reform movements, the memoirs of Devaki Nilayamgode and Lalithambika Antherjanam elucidate the simultaneous prevalence of untouchability and casteism with gender discrimination. Devaki Nilayamgode's narrative explicates that "if someone who had not had a bath, or a lower-caste Shudra who was washing clothes, happened to splash some water on them, the antharjanams were required to go for another dip in the tank" (Nilayamgode 2011:20). In fact the memoirs consciously or unconsciously equate the subaltern status and inferiority imposed by the caste system with that of the prejudiced maltreatment of women.

\section{Family, Gender and Societal Reform}

The memoir acknowledges the role of the early twentieth century Brahmin reforms on the alteration and transformation of persisting family structure. Domesticity occurs as a self exhausting force, redefining and restraining the contours of the women inside the boundaries of the familial space. Both the memoirs significantly explore the societal plight and the impulse associated with the reform movements pertaining to women. According to Antherjanam, the male reformers accentuated on the plight of women when they "realized that true social progress could not be achieved unless women were granted freedom, and efforts were initiated in this direction" (Antherjanam 1998:145).

\section{The "Elite" Subaltern Women}

Reflecting the feminine self has always been a Herculean task for namboodiri women whose desire and individuality was often hidden under the cloak of respectability. Common under 
currents of subjugation and resistance characterise the selected autobiography of the "dominant" women. Autobiography had persistently figured as a means and medium of critical self evaluation for women. They portray the oppressed women's capability of significant critical reflections, even during the phase of anguish and suppression.

Even while using these translated life-writings as evaluative tools of the life standards of a particular section of women, I agree with the fact that examining these self-writings does not guarantee a unified interpretation of the lives of the women belonging to the particular community, though it renders a general awareness about their communal wise suffering and subaltern status. In this regard as the author of the paper I would like to point out that I became perfectly aware of the persisting differential gender equations existing within the same community.

However in the due course of the paper what attracted my attention was the fact that despite the emotional and physical anguish inflected by the patriarchal aggrandisement of power, the authors and translators critique the structure of the society as wholly responsible rather than exclusively accusing the male section of the family or the society. A tone of societal pity and condemnation characterises the translated writings.

The translated memoirs in fact transform the feminine self into a global written referent in relation to the Kerala society and the culture. Howsoever this transference also facilitates the transcendence of the limitations imposed by gender binaries through the open assertion of the feminist authors and translators. As rightly pointed out when "women write their own metaphors of cultural production, it may be possible to consider the acts of authoring, 
creating, or legitimizing a text outside of the gender binaries" (Chamberlain 2000:327).

Transgressing the binaries, the feminine self in the translated narratives emerge as a literary and social construct. The protagonists explicate the possibility of self discovery as self- narration becomes self explication. Self -scripting and translation of the lives of the Namboodiri women thus becomes an act of transgression facilitating the revolt of the cloistered subaltern namboodiri women and entailing her satisfaction against the established moral rules and codes.

So far the paper has explored the multiple dimensions and nuances associated with the depiction of the Namboodiri women in the selected life writings. It had endeavoured to portray the subaltern status and enforced inferiority on the Brahmin women in the early Kerala society and their subsequent resistance, globally recreated through the linguistic tool of translated life-writings. In short, the paper has endeavoured to explore the portrayal of Kerala history, society and culture in the translations and the struggles encountered by the translators in conveying the gendered cultural nuances across the globe through the medium of English language.

\section{Bibliography}

\section{Primary References:}

Nilayamgode, Dēvaki. 2011. Antharjanam: Memoirs of a Namboodiri Woman. Translated by Indira Menon and Radhika P. Menon. New Delhi: Oxford University Press.

Antherjanam, Lalithāmbika. 1998. Cast Me Out If You Will: Stories and Memoir. Translated by Gita Krishnakutty. Calcutta: Stree. 
Divya.N.

\section{Secondary References:}

Caine, Barbara. "Feminist Biography and Feminist History." Women's History Review 3, no. 2 (1994): 247-61. Accessed January 5, 2016. JSTOR.

Chamberlain, Lori. 2000. "Gender and the Metaphorics of Translation." In The Translation Studies Reader, edited by Lawrence Venuti, 314-30. London: Routledge.

Cixous, Hélène. "The Laugh of the Medusa." Translated by Keith Cohen and Paula Cohen. Signs 1, no. 4 (1976): 875-93. Accessed March 5, 2016. JSTOR.

Derrida, Jacques. 1985. The Ear of the Other: Otobiography, Transference, Translation. Edited by Christie McDonald and Claude Lévesque. Translated by Peggy Kamuf. New York: Schocken Books.

Devika, J. 2007. Engendering Individuals: The Language of Reforming in Early Twentieth Century Keralam. Hyderabad: Orient Longman.

---. "Introduction.” In Antharjanam :Memoirs of a Namboodiri Woman, by Devaki

Nilayamgode, translated by Radhika Menon and Indira Menon, xvii-xxxi. Newdelhi: Oxford University Press, 2011.

Krishnankutty, Gita.1998. "Introduction." In Cast Me Out If You Will: Stories and Memoir, by Lalithambika Antherjanam, translated by Gita Krishnankutty, xiii-xxxi. Calcutta: Stree.

Menon, Indira. "Translators' Notes." In Antharjanam:Memoirs of a Namboodiri Woman, by Devaki Nilayamgode, translated by Indira Menon and Radhika Menon, ix-xi, xi-xv. New Delhi: Oxford University Press, 2011.

Simon, Sherry. 1996. Gender in Translation: Cultural Identity and the Politics of Transmission. London and New York: Routledge.

Tharu, Susie. 1998. "Foreword." In Cast Me Out If You Will: Stories and Memoir, by Lalithambika Antherjanam, translated by Gita Krishnankutty, vii-ix. Calcutta: Stree. 